\title{
Involvement of the mitogen-activated protein kinase signaling pathway in osteoprotegerin-induced inhibition of osteoclast differentiation and maturation
}

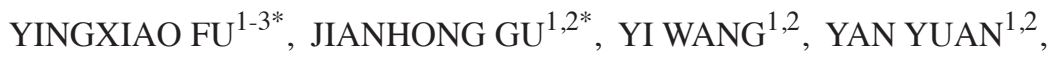 \\ XUEZHONG LIU ${ }^{1,2}$, JIANCHUN BIAN ${ }^{1,2}$ and ZONGPING LIU ${ }^{1,2}$ \\ ${ }^{1}$ Department of Clinical Veterinary Medicine, College of Veterinary Medicine, Yangzhou University; \\ ${ }^{2}$ Jiangsu Co-Innovation Center for Prevention and Control of Important Animal Infectious Diseases and Zoonoses, \\ Yangzhou, Jiangsu 225009; ${ }^{3}$ Department of Bioscience, Bengbu Medical College, Bengbu, Anhui 233000, P.R. China
}

Received September 28, 2014; Accepted July 14, 2015

DOI: $10.3892 / \mathrm{mmr} .2015 .4284$

\begin{abstract}
The present study aimed to determine whether the mitogen-activated protein kinase (MAPK) signaling pathway is involved in the osteoprotegerin (OPG)-mediated inhibition of osteoclast differentiation and maturation. RAW264.7 cells were incubated with macrophage colony-stimulating factor (M-CSF) and receptor activator of nuclear factor- $\kappa \mathrm{B}$ ligand (RANKL) to stimulate osteoclastogenesis and treated with various concentrations of OPG, an inhibitor of osteoclast differentiation. The differentiation and activation of osteoclasts were monitored by tartrate-resistant acid phosphatase staining and bone resorption assays. The phosphorylation levels of p38-MAPK, c-Jun N-terminal kinase (JNK)-MAPK and extracellular signal-regulated kinase (ERK)-MAPK in the different treatment groups were determined by western blot analysis. The results confirmed that M-CSF + RANKL stimulated the differentiation and activation of osteoclasts as well as the phosphorylation of p38-MAPK, JNK-MAPK and ERK-MAPK in osteoclasts, which was attenuated by OPG treatment. These findings indicated that the MAPK signaling pathway is involved in the regulation of osteoclastogenesis and in the OPG-mediated inhibition of osteoclast differentiation and activation.
\end{abstract}

\section{Introduction}

Mitogen-activated protein kinases (MAPKs) are serine/threonine protein kinases. The conserved MAPK signaling pathway

Correspondence to: Dr Zongping Liu, Department of Clinical Veterinary Medicine, College of Veterinary Medicine, Yangzhou University, 88 Daxuenanlu Road, Yangzhou, Jiangsu 225009, P.R. China E-mail: liuzongping@yzu.edu.cn

\section{${ }^{*}$ Contributed equally}

Key words: osteoprotegerin, osteoclast, mitogen-activated protein kinase signaling pathway, osteoclastogenesis exists in all eukaryotes and is considered a central hub in the regulation of cellular processes, including growth, proliferation, division, cell cycle progression, apoptosis, necrosis and cell-cell interactions (1-3). The signaling cascade includes no less than three enzymes that are activated in sequence: An MAPK kinase kinase, an MAPK kinase and an MAPK (1). These enzymes all possess 11 conserved sub-domains and are activated via phosphorylation of amino acid residues (4). Rossomando et al (5) identified the extracellular signal-regulated kinase (ERK)-MAPK in mammalian cells in 1991, while the stress-activated protein kinase (SAPK)-MAPK and p38-MAPK were discovered subsequently $(6,7)$. Together, these three enzymes are the main members of the MAPK family.

Osteoclasts are specialized multinucleated cells that execute the catabolic phase of bone remodeling $(8,9)$. Bone remodeling is a persistent physiological process in healthy humans and animals that is initiated by osteoclasts and is critical for bone mass homeostasis $(10,11)$. Osteoclasts are responsible for bone resorption, while osteoblasts are responsible for bone matrix generation and mineralization. Together, these processes lead to whole bone remodeling (12). In instances where these processes become unbalanced, bone mass may increase or decrease abnormally and cause diseases including osteopetrosis, osteoporosis, chondropathy and rheumatoid arthritis (13). Receptor activator of nuclear factor $\kappa \mathrm{B}$ ligand (RANKL) is a member of the tumor necrosis factor (TNF) ligand superfamily and is an essential cytokine for osteoclastogenesis (14). RANKL is produced by osteoblasts/stromal cells and combines with its receptor, RANK, which is expressed on the surface of osteoclast precursors (14). RANKL/RANK association triggers the signaling cascades involved in differentiation and activation of osteoclasts (9). Osteoprotegerin (OPG), a protein generated by osteoblast/stromal cells, acts as a decoy receptor for RANKL and inhibits RANKL/RANK association, inhibiting the development of osteoclasts (15). The RANK/RANKL/OPG axis regulates bone metabolism and osteoclastogenesis (14).

Previous studies have demonstrated that ERK-MAPK, c-Jun N-terminal kinase (JNK)-MAPK and p38-MAPK 
are involved in the RANKL/RANK signaling pathway, which regulates osteoclast differentiation, maturation and survival (16-19). It is, however, unknown whether the MAPK signaling pathway is involved in OPG-induced inhibition of osteoclast development. The present study attempted to examine the involvement of the MAPK signaling pathway by utilizing specific inhibitors of the MAPK pathway in order to test whether OPG or specific kinase inhibitors may have potential use in the treatment of bone loss-associated diseases resulting from dynamic bone resorption of osteoclasts.

\section{Materials and methods}

Cells and reagents. The murine monocyte/macrophage cell line RAW264.7 was purchased from the American Type Culture Collection (ATCC, Manassas, VA, USA). The primary rabbit anti-phospho p38-MAPK polyclonal antibody (cat. no. SAB4504095), Acid Phosphatase kit 387-A [tartrate-resistant acid phosphatase (TRAP) staining kit] and the specific inhibitors U0126, SB202190, SP600125 were obtained from Sigma-Aldrich (St. Louis, MO, USA). The primary rabbit anti-ERK1/2 polyclonal antibody (cat. no. 06-642) was purchased from Millipore Corporation (Billerica, MA, USA). The primary anti-p38-MAPK polyclonal (cat. no.9212S), rabbit anti-phospho SAPK/JNK monoclonal (cat. no. 4671S), rabbit anti-phospho ERK1/2 monoclonal (cat. no. 9101S), rabbit anti $\beta$-actin polyclonal (cat. no. 4970S) and rabbit anti-SAPK/JNK polyclonal (cat. no. 9258S) antibodies were purchased from Cell Signaling Technology Inc. (Beverly, MA, USA). The rabbit anti-sheep immunoglobulin $\mathrm{G}(\mathrm{IgG})$ horseradish peroxidase (HRP)-conjugated secondary antibody (cat. no. sc-2770) was obtained from Santa Cruz Biotechnology (Dallas, TX, USA). Macrophage colony-stimulating factor (M-CSF), RANKL and OPG were purchased from PeproTech Inc. (Rocky Hill, NJ, USA). Bovine cortical bone was purchased from a slaughterhouse (Yangzhou, China) and was sawed into slices by a saw microtome (SP1600; Leica Microsystems, Wetzlar, Germany) at Shanghai Ninth People's Hospital Affiliated to Shanghai JiaoTong University School of Medicine (Shanghai, China).

TRAP-positive cell staining and bone resorption activity assay. RAW264.7 cells were cultured in Dulbecco's modified Eagle's medium (DMEM) containing 10\% fetal bovine serum (FBS; Gibco-BRL, Carlsbad, CA, USA), 2 mM/1 L-glutamine, $100 \mathrm{U} / \mathrm{ml}$ penicillin and $100 \mu \mathrm{g} / \mathrm{ml}$ streptomycin at $37^{\circ} \mathrm{C}$ in a humidified atmosphere of $5 \% \mathrm{CO}_{2}$. For studies on osteoclast differentiation, cells were adjusted to a concentration of $1.5 \times 10^{4}$ cells $/ \mathrm{ml}$ in $\alpha$-Minimum Essential Medum $(\alpha-M E M)$ containing $10 \% \mathrm{FBS}, 2 \mathrm{mM} / 1$ L-glutamine, $100 \mathrm{U} / \mathrm{ml}$ penicillin and $100 \mu \mathrm{g} / \mathrm{ml}$ streptomycin. Cells were seeded in 96-well and 48 -well plates with bovine cortical bone slices. After a $24 \mathrm{~h}$ of incubation, the medium was replaced with serum-free $\alpha$-MEM containing M-CSF $(25 \mathrm{ng} / \mathrm{ml})$ and RANKL $(30 \mathrm{ng} / \mathrm{ml})$, and the cells were cultured for another $48 \mathrm{~h}$. At that time-point, in the presence of M-CSF + RANKL, $0,10,20,50$ or $100 \mathrm{ng} / \mathrm{ml}$ OPG was added and cells were incubated for an additional three days.

At the end of the incubation, TRAP staining of osteoclasts and bone resorption activity assays was performed according to the manufacturer's instructions. The number of TRAP-positive cells in each group was counted and compared. Briefly, TRAP-positive cells in ten randomized visual fields from three random wells were counted using an inverted microscope (Leica Microsystems GmbH, Wetzlar, Germany). At the same time, bone resorption by differentiated osteoclasts in bovine cortical bone slices was calculated in the different groups. The bone slices co-cultured with differentiated osteoclasts were removed from the plates. Any remaining cells on bone slices were removed by ultrasonic cleaning. The resorption lacunae on bone slices were observed using an environmental scanning electron microscope (XL30-ESEM; Philips, Eindhoven, The Netherlands). The volume of resorption lacunae was determined by professional image analysis software (version 1.0; JEDA Technologies, Nanjing, China).

Western blot analysis. RAW264.7 cells were cultured in $\alpha$-MEM containing $10 \%$ FBS, $2 \mathrm{mM} / 1 \mathrm{~L}$-glutamine, $100 \mathrm{U} / \mathrm{ml}$ penicillin and $100 \mu \mathrm{g} / \mathrm{ml}$ streptomycin in six-well plates for $24 \mathrm{~h}$ at a concentration of $1.5 \times 10^{4}$ cells $/ \mathrm{ml}$. Medium was then replaced with serum-free $\alpha$-MEM with M-CSF $(25 \mathrm{ng} / \mathrm{ml})+$ RANKL $(30 \mathrm{ng} / \mathrm{ml})$ and the cells were cultured for a further $48 \mathrm{~h}$. Subsequent treatment was dependent on the assay type. For time-course studies, $100 \mathrm{ng} / \mathrm{ml} \mathrm{OPG}$ was added in the presence of M-CSF + RANKL and cells incubated for $15,30,60$ or $120 \mathrm{~min}$. For concentration gradient studies, $0,10,20,50$ or $100 \mathrm{ng} / \mathrm{ml}$ OPG were added in the presence of M-CSF + RANKL and cells were incubated for $30 \mathrm{~min}$. For studies on inhibition of the MAPK signaling pathway, complete medium was removed and replaced with serum-free medium. The cells were pre-treated with $100 \mathrm{ng} / \mathrm{ml} \mathrm{OPG}$ and either $0.2 \mu \mathrm{M}$ U0126 (a specific inhibitor of the ERK-MAPK signaling pathway), $10 \mu \mathrm{M} \mathrm{SB} 202190$ (a specific inhibitor of the p38-MAPK signaling pathway) or $10 \mu \mathrm{M}$ SP600125 (a specific inhibitor of the JNK-MAPK signaling pathway) for $30 \mathrm{~min}$. M-CSF + RANKL were then added for an additional $30 \mathrm{~min}$.

Following incubation, cells from each experimental group were collected and lysed in $180 \mu \mathrm{l}$ radioimmunoprecipitation assay (RIPA) buffer with $1 \%$ (v/v) PMSF for 30 min with intermittent vibration. After sonication, the solution of lysed cells was centrifuged $\left(12,000 \mathrm{xg}\right.$ for $10 \mathrm{~min}$ at $\left.4^{\circ} \mathrm{C}\right)$ and the supernatants were extracted. The total protein concentration was $6-15 \mathrm{mg} / \mathrm{ml}$. The protein was loaded (60-150 $\mu \mathrm{g}$ per lane) and were separated, transferred, blocked and incubated overnight at $4^{\circ} \mathrm{C}$ with primary anti-phospho p38-MAPK, anti-phospho JNK-MAPK, anti-phospho ERK-MAPK, anti-p38-MAPK, anti-JNK-MAPK, anti-ERK-MAPK or anti- $\beta$-actin antibodies diluted in 5\% BSA-Tris-buffered saline with Tween-20 (TBST). Following incubation with the primary antibodies, the samples were incubated with anti-sheep IgG HRP secondary antibody diluted in 5\% BSA-TBST for $90 \mathrm{~min}$ at room temperature. Immunoreactive proteins were visualized by enhanced chemiluminescence (ECL) using ECL-plus detection reagents (Thermo Fisher Scientific, Waltham, MA, USA). The experiments were repeated three times.

\section{Results}

$O P G$ inhibits the differentiation and bone resorption activities of osteoclasts. Multinucleated TRAP-positive cells were 
A
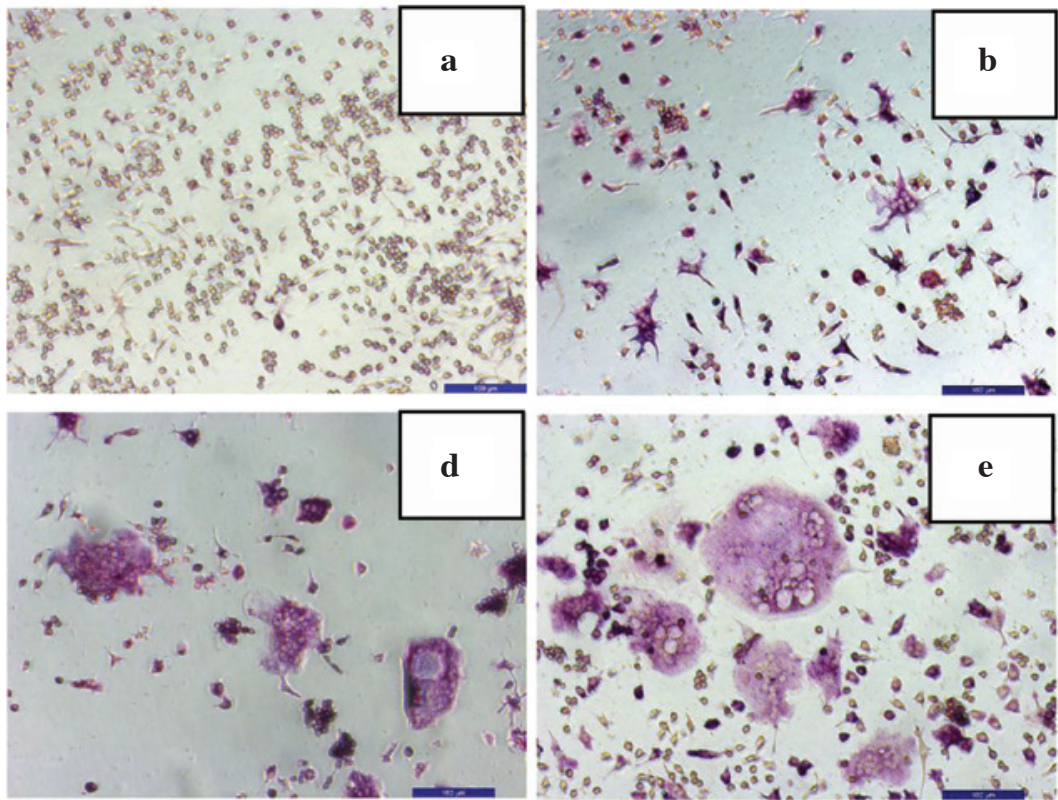
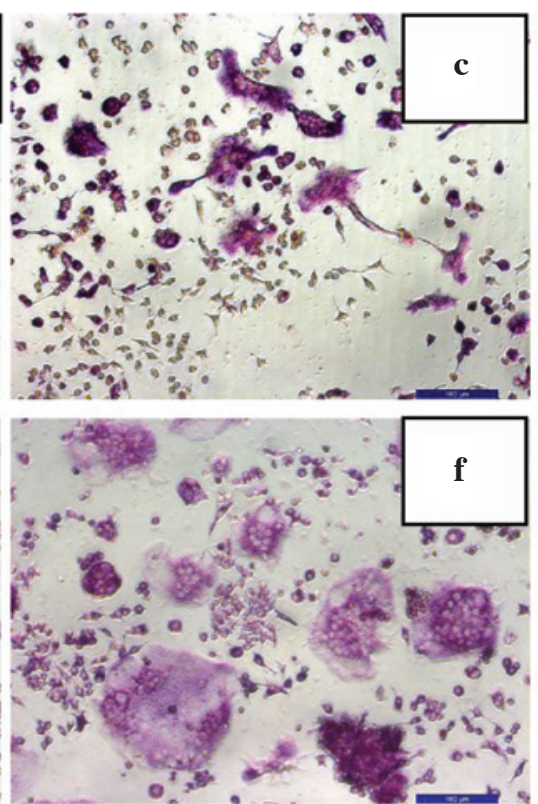

B
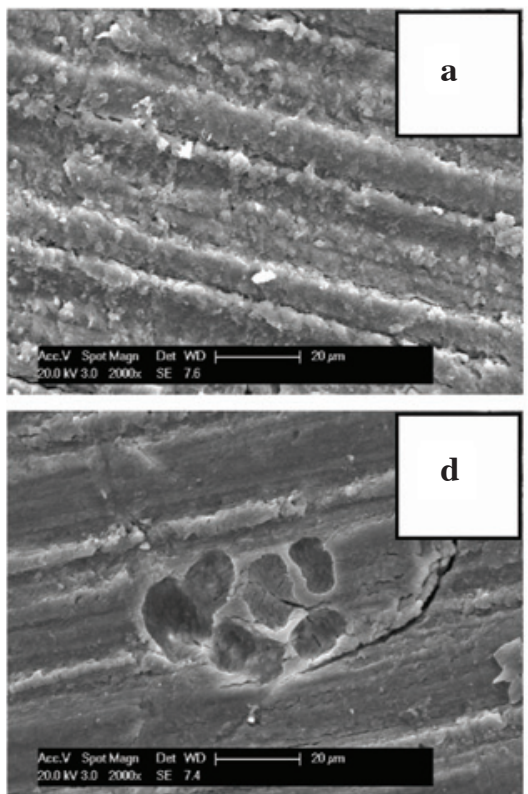
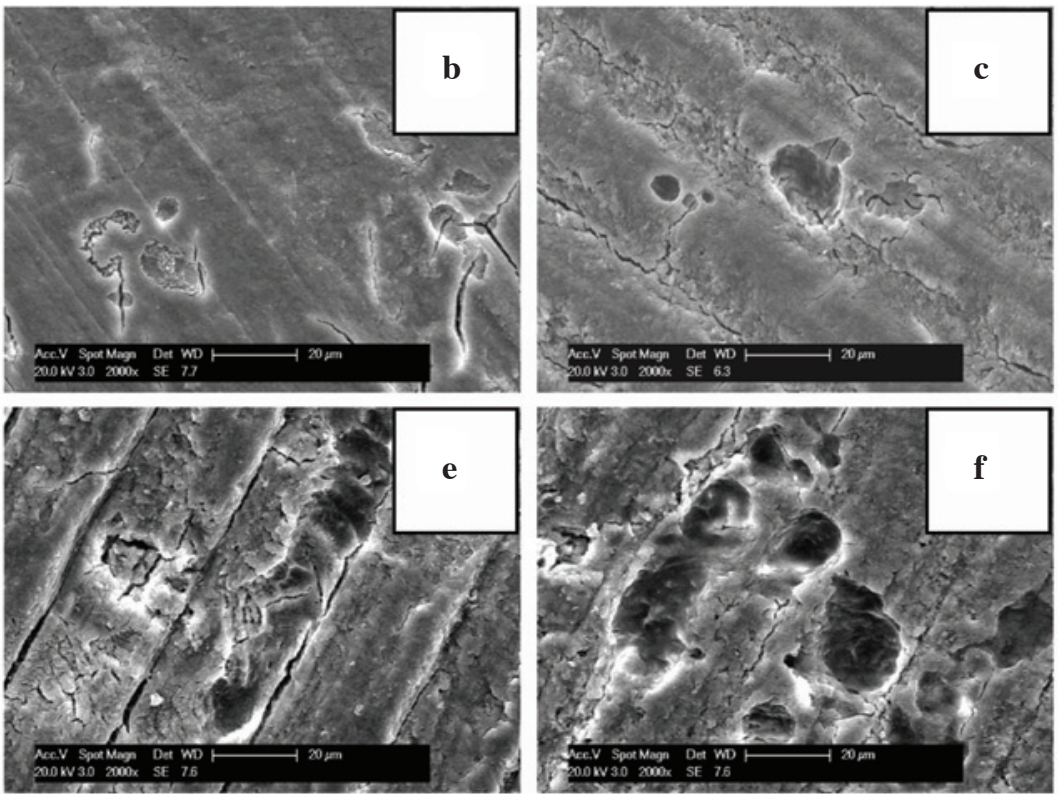

Figure 1. OPG inhibits differentiation and bone resorption activity of osteoclasts. (A) Light microscopic images showing the inhibition of tartrate-resistant acid phosphatase-positive multinucleated osteoclast differentiation in M-CSF + RANKL-induced RAW264.7 cells by OPG (original magnification, x200; scale bar, $100 \mu \mathrm{m}$ ). (B) Electron micrographs showing the inhibitory effects of OPG on osteoclast bone resorption activity (original magnification, $\mathrm{x} 2,000$; scale bar, $20 \mu \mathrm{m}$ ). Ten visual fields were selected randomly and counted in each well for each group. (a) RAW264.7 cells (control); (b-f) M-CSF + RANKL-induced RAW264.7 cells treated with (b) $100 \mathrm{ng} / \mathrm{ml}$ OPG; (c) $50 \mathrm{ng} / \mathrm{ml} \mathrm{OPG;} \mathrm{(d)} 20 \mathrm{ng} / \mathrm{ml} \mathrm{OPG;} \mathrm{(e)} 10 \mathrm{ng} / \mathrm{ml} \mathrm{OPG;} \mathrm{(f)} \mathrm{No} \mathrm{OPG.} \mathrm{OPG,} \mathrm{steoprotegerin;} \mathrm{M-CSF,} \mathrm{macro-}$ phage colony-stimulating factor; RANKL, receptor activator of nuclear factor- $\mathrm{kB}$ ligand.

observed in M-CSF + RANKL-treated RAW264.7 cells after four days of incubation. The differentiated cells showed characteristic bone resorption activity, as indicated by the observation that cells corroded the bone slices to produce cavities. OPG treatment reduced the number of multinucleated TRAP-positive cells and inhibited the bone resorption activity of differentiated cells in a concentration-dependent manner as compared to those in the control group (Fig. 1A and B).

OPG affects the MAPK signaling pathway in a time-dependent manner. All three branches of the MAPK signaling pathway, namely p38-MAPK, JNK-MAPK and ERK-MAPK, were activated in the M-CSF + RANKL-treated RAW264.7 cells within $15 \mathrm{~min}$ of incubation. Phosphorylation levels of p38-MAPK peaked within 15 min and subsequently declined. Phosphorylation levels of JNK-MAPK and ERK-MAPK peaked within $30 \mathrm{~min}$ and declined afterwards. The addition of OPG decreased the phosphorylation levels of p38-MAPK, JNK-MAPK and ERK-MAPK in a time-dependent manner (Fig. 2).

OPG inhibits the MAPK signaling pathway in a concentration-dependent manner. Compared to those in the RAW264.7 control group, the phosphorylation levels of 


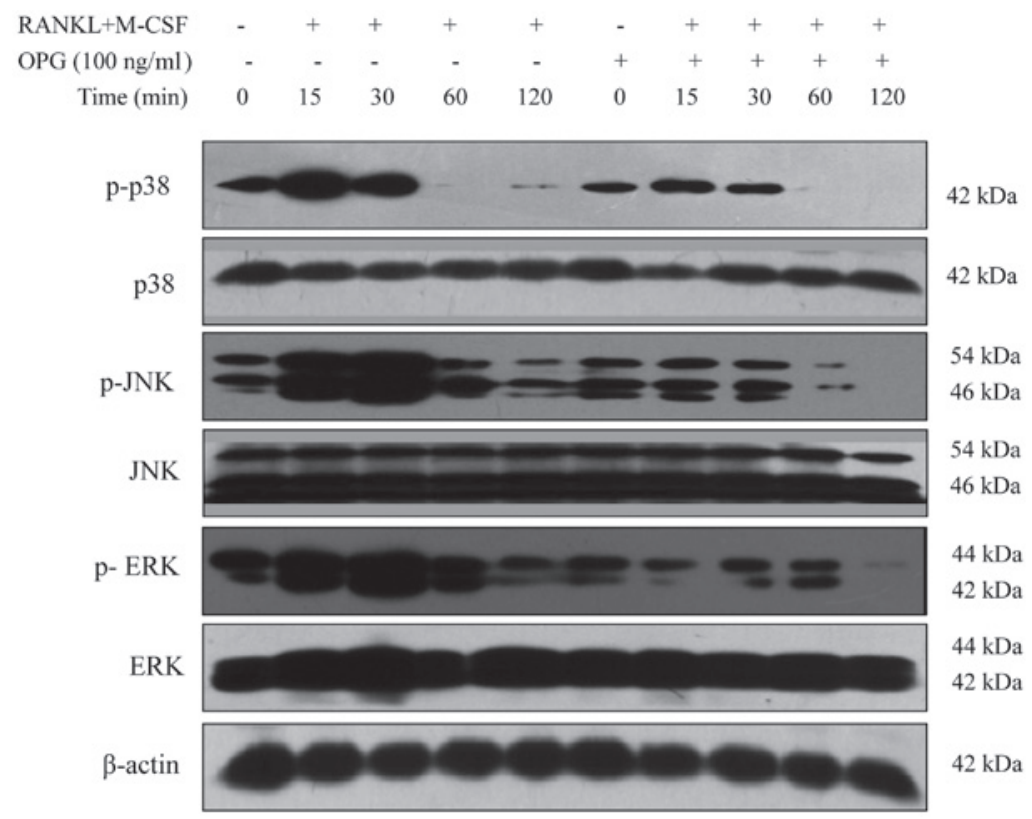

Figure 2. Effects of OPG on phosphorylation levels of proteins involved in the mitogen-activated protein kinase signaling pathway. $100 \mathrm{ng} / \mathrm{ml} \mathrm{OPG}$ were added in the presence of M-CSF + RANKL and treatment was sustained for 15, 30,60 or $120 \mathrm{~min}$. Following incubation, cells were collected and total protein extracted and analyzed by western blotting. Phosphorylation levels of the signaling proteins are shown. Each experiment was repeated three times. OPG, steoprotegerin; M-CSF, macrophage colony-stimulating factor; RANKL, receptor activator of nuclear factor- $\kappa \mathrm{B}$ ligand; ERK, extracellular signal-regulated kinase; p-JNK, phosphorylated c-Jun N-terminal kinase.

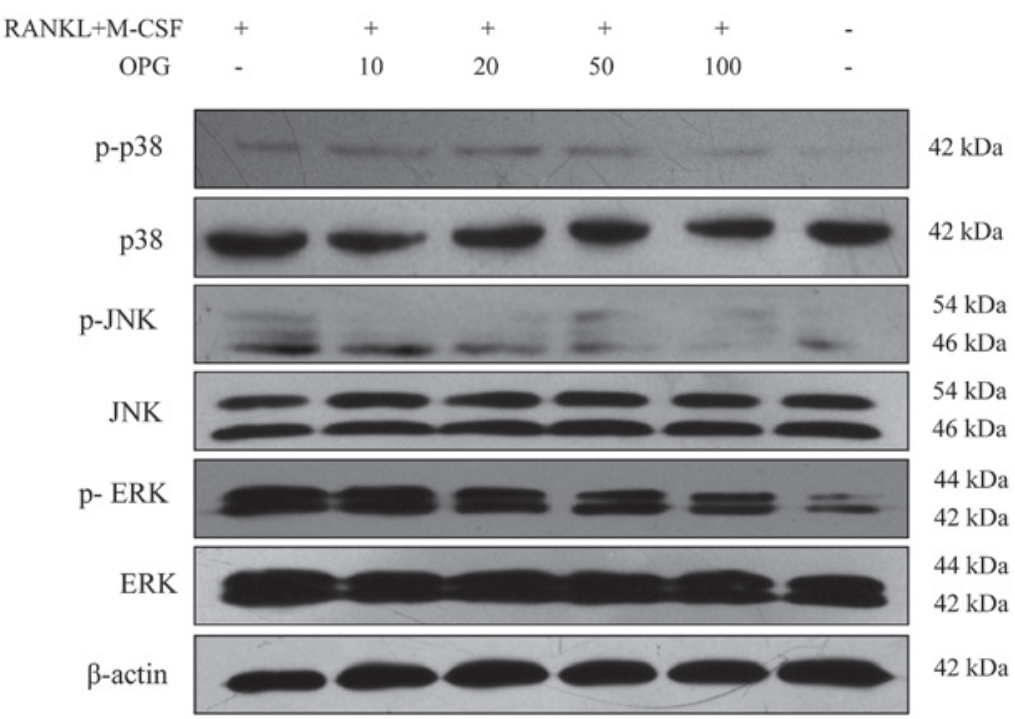

Figure 3. Effects of OPG concentration on the phosphorylation of mitogen-activated protein kinase signaling pathway proteins. 0, 10, 20,50 or $100 \mathrm{ng} / \mathrm{ml}$ OPG were added in the presence of M-CSF + RANKL and treatment was sustained for 30 min. Following incubation, cells were collected and total protein was extracted and analyzed by western blotting. Phosphorylation levels of the signaling proteins are shown. Each experiment was repeated three times. OPG, steoprotegerin; M-CSF, macrophage colony-stimulating factor; RANKL, receptor activator of nuclear factor- $\mathrm{kB}$ ligand; ERK, extracellular signal-regulated kinase; p-JNK, phosphorylated c-Jun N-terminal kinase.

p38-MAPK, JNK-MAPK and ERK-MAPK increased with $\mathrm{M}-\mathrm{CSF}+\mathrm{RANKL}$ treatment. Of note, OPG decreased the phosphorylation levels of p38-MAPK, JNK-MAPK and ERK-MAPK in a concentration-dependent manner (Fig. 3).

OPG inhibits osteoclast differentiation via the MAPK signaling pathway. Specific inhibitors of p38-MAPK, JNK-MAPK and ERK-MAPK were employed in the present study in order to test the involvement of the MAPK signaling pathway in the effects of OPG on osteoclast differentiation. The results further confirmed that the three signaling pathways are involved in the differentiation and activation of osteoclasts and that OPG affects the differentiation and activation of osteoclasts.

\section{Discussion}

In view of the fact that the amounts of purified primary osteoclasts required for signal transduction studies were prohibitive, RAW264.7 cells were used to study the MAPK signaling pathway. These cells are considered optimal osteoclast 

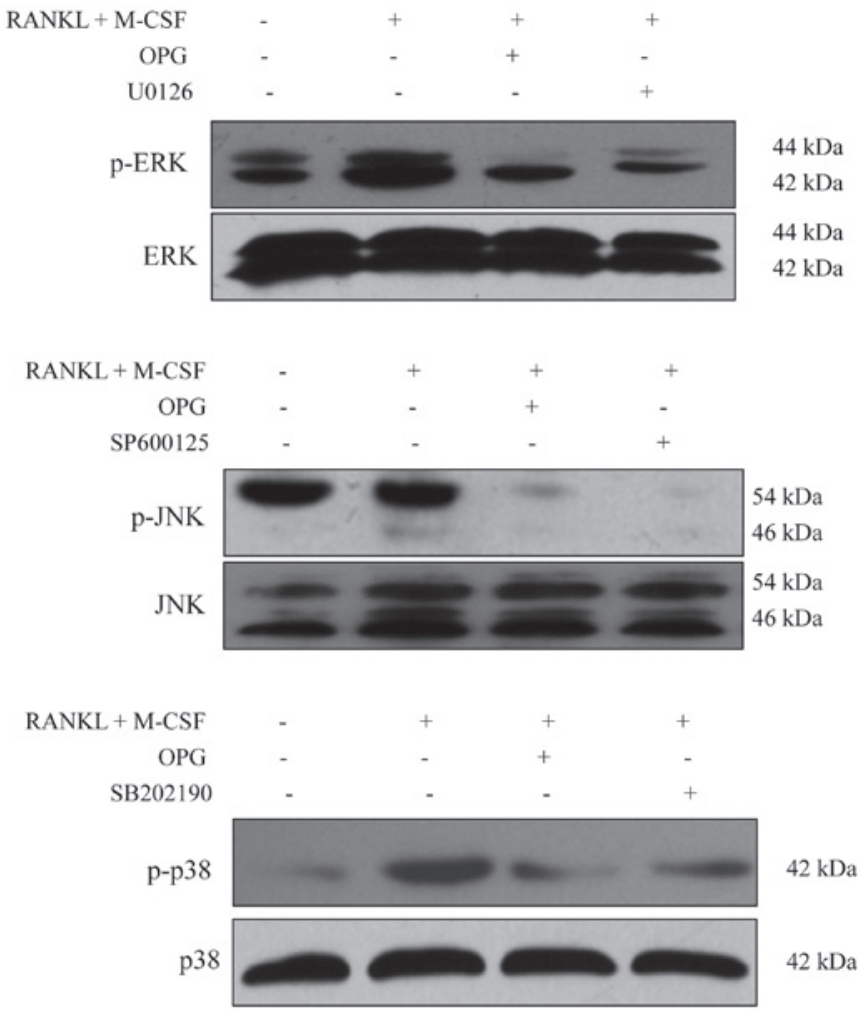

Figure 4. Effects of the signaling inhibitors on the MAPK signaling pathway in OPG-inhibited osteoclastogenesis. The cells were pre-treated with $100 \mathrm{ng} / \mathrm{ml}$ OPG and $0.2 \mu \mathrm{M}$ U0126 (specific inhibitor of the ERK-MAPK signaling pathway), $10 \mu \mathrm{M} \mathrm{SB} 202190$ (specific inhibitor of the p38-MAPK signaling pathway) or $10 \mu \mathrm{M}$ SP600125 (specific inhibitor of the JNK-MAPK signaling pathway) in the corresponding experimental groups for $30 \mathrm{~min}$ M-CSF + RANKL were then added into the corresponding experimental groups for a further $30 \mathrm{~min}$. The cells were then collected, total protein was extracted and changes in the levels of signaling proteins were detected by western blot analysis. Each experiment was repeated three times. OPG, steoprotegerin; M-CSF, macrophage colony-stimulating factor; RANKL, receptor activator of nuclear factor- $\mathrm{\kappa B}$ ligand; MAPK, mitogen-activated protein kinase; ERK, extracellular signal-regulated kinase; p-JNK, phosphorylated c-Jun N-terminal kinase.

precursors and have been extensively applied in in vitro studies on osteoclasts (20-22). A previous study by our group demonstrated that M-CSF + RANKL induces RAW264.7-cell differentiation into osteoclasts on a morphological as well as molecular basis; and showed that this process was inhibited by OPG (23). These results laid a foundation for the present study, which aimed to investigate the involvement of the MAPK signaling pathway in this process. Over the previous decades, multiple studies have demonstrated that OPG inhibits the differentiation and activation of osteoclasts (24-26). Few of these studies, however, have focused on the associated signal transduction mechanisms. The present study demonstrated that the MAPK signaling pathway is involved in the $\mathrm{M}-\mathrm{CSF}+\mathrm{RANKL}$-induced differentiation and activation of osteoclasts, which can be modulated by OPG.

ERK-MAPK, JNK-MAPK and p38-MAPK in osteoclasts and osteoclast precursors are activated by the combination of RANKL and RANK (16-18,27). p38-MAPK is activated by MAPK kinase 6 , which is activated by the combination of RANKL and RANK, and subsequently phosphorylates microphthalmia-associated transcription factor (MITF), promoting the differentiation of osteoclasts (28). Lee et al (17) and Li et al (18) further confirmed that p38-MAPK is involved in the differentiation of osteoclasts through studies using specific signaling inhibitors $(17,18)$. Previous studies suggested that ERK-MAPK was involved in survival of osteoclasts rather than bone resorption activities $(29,30)$. Tumor necrosis factor receptor-associated factor (TRAF)-6 is an adapter protein that is the binding site of the RANK cytoplasmic motif PFQEP369-373 (31). RANK regulates the development of osteoclasts using TRAF-6 as an intermediary (32). Transforming growth factor beta-activated kinase 1/MAP3K7 binding protein 2 are proteins downstream of TRAF-6, which activate JNK-MAPK and p38-MAPK (33). Downstream transcription factors of ERKs and JNKs include activator protein (AP)-1, the Fos dipolymer family (c-Fos, FosB, Fra-1, and Fra-2), and the Jun family (c-Jun, JunB, and JunD) (25). These transcription factors are master regulators of osteoclast differentiation $(25,34)$. ERK-MAPK activates c-Fos, while JNK-MAPK enhances the transcriptional activity of AP-1 through the phosphorylation of c-Jun (35). Furthermore, AP-1 triggers the gene-encoding matrix metalloproteinase and alkaline phosphatase, promoting the differentiation, survival and fusion of osteoclast precursors, and advancing the activation of mature osteoclasts as well $(36,37)$. Activated ERK enters the nucleus of mature macrophages and sequentially activates the transcription factor Elk, associating with the cis-regulating element located in the promoter region of the c-Fos gene, and driving the differentiation of the mature macrophages into osteoclast precursors (38). M-CSF specifically stimulates the growth of macrophage colonies (39). M-CSF has an important role in the differentiation and survival of osteoclast precursors as well as the survival of mature osteoclasts $(40,41)$. Weilbaecher et al (42) suggested that M-CSF impacts the development of osteoclasts through MAPK signaling pathway activation, further activating MITF and transcription factor binding to immunoglobulin heavy constant mu enhancer 3, and promoting the differentiation of osteoclasts and the formation of TRAP-positive multinucleated cells. In addition, the present study confirmed that ERK-MAPK, JNK-MAPK and p38-MAPK were phosphorylated during $\mathrm{M}-\mathrm{CSF}+\mathrm{RANKL}$-induced osteoclastogenesis.

Simonet et al (24) reported that OPG is involved in the regulation of bone density by specifically inhibiting osteoclastogenesis. Subsequent studies suggested that the differentiation and activation of osteoclasts were blocked by OPG through direct and indirect effects. OPG binds to RANKL in a competitive manner with respect to RANK, impeding the RANKL-RANK signaling cascade (25), by an indirect mechanism. In addition, OPG can induce apoptosis in mature osteoclasts by damaging cellular structures such as the F-actin ring $(43,44)$, via a direct mechanism. In the present study, OPG was added to differentiating osteoclast precursors rather than differentiated osteoclasts. It appears, therefore, that OPG interfered with the differentiation of osteoclasts via the indirect mechanism. Theoleyre et al (20) investigated the direct influences of OPG on osteoclasts and demonstrated that OPG induces the phosphorylation of ERK1/2 and p38 in differentiated osteoclasts. The study suggested that OPG had specific inhibitory activity on the development of osteoclasts via ERK1/2 phosphorylation (20). In the present study, 
however, ERK1/2 phosphorylation levels were found to be decreased alongside the inhibition of osteoclastogenesis by OPG. A possible interpretation of this discrepancy is that ERK1/2 phosphorylation levels were increased during apoptosis of osteoclasts in the study by Theoleyre et al (20).

In conclusion, the findings of the present study indicated that the MAPK signaling pathway is involved in the regulation of osteoclastogenesis as well as in the OPG-mediated inhibition of osteoclast differentiation and activation.

\section{Acknowledgements}

The present study was supported by the National Natural Science Foundation of China (nos. 31172373, 31372495 and 31302154), a Project Funded by the Priority Academic Program Development of Jiangsu Higher Education Institutions, the National Research Foundation for the Doctoral Program of Higher Education of China (no. 20113250110003) and the Anhui Provincial Natural Science Foundation (no. 1508085QH172). Furthermore, the authors would like to thank the ACCDON LLC (Woburn, MA, USA) for the professional English editing service.

\section{References}

1. Zhang W and Liu HT: MAPK signal pathways in the regulation of cell proliferation in mammalian cells. Cell Res 12: 9-18, 2002.

2. Seger R and Krebs EG: The MAPK signaling cascade. FASEB J 9: 726-735, 1995.

3. Sompallae R, Stavropoulou V, Houde M and Masucci MG: The MAPK signaling cascade is a central hub in the regulation of cell cycle, apoptosis and cytoskeleton remodeling by tripeptidyl-peptidase II. Gene Regul Syst Bio 2: 253-265, 2008.

4. Robinson MJ and Cobb MH: Mitogen-activated protein kinase pathways. Curr Opin Cell Biol 9: 180-186, 1997.

5. Rossomando AJ, Sanghera JS, Marsden LA, Weber MJ, Pelech SL and Sturgill TW: Biochemical characterization of a family of serine/threonine protein kinases regulated by tyrosine and serine/threonine phosphorylations. J Biol Chem 266 20270-20275, 1991.

6. Brewster JL, de Valoir T, Dwyer ND, Winter E and Gustin MC: An osmosensing signal transduction pathway in yeast. Science 259 1760-1763, 1993.

7. Kyriakis JM and Avruch J: pp54 microtubule-associated protein 2 kinase. A novel serine/threonine protein kinase regulated by phosphorylation and stimulated by poly-L-lysine. J Biol Chem 265: 17355-17363, 1990.

8. Jansen ID, Vermeer JA, Bloemen V, Stap J and Everts V: Osteoclast fusion and fission. Calcif Tissue Int 90: 515-522, 2012

9. Honma M, Ikebuchi Y, Kariya Y and Suzuki H: Regulatory mechanisms of RANKL presentation to osteoclast precursors. Curr Osteoporos Rep 12: 115-120, 2014.

10. Nakashima T: Regulation mechanism of bone remodeling. Kokubyo Gakkai Zasshi 80: 75-80, 2013 (In Japanese).

11. Lemaire V, Tobin FL, Greller LD, Cho CR and Suva LJ: Modeling the interactions between osteoblast and osteoclast activities in bone remodeling. J Theor Biol 229: 293-309, 2004.

12. Boyce BF and Xing L: Functions of RANKL/RANK/OPG in bone modeling and remodeling. Arch Biochem Biophys 473: 139-146, 2008

13. Wright HL, McCarthy HS, Middleton J and Marshall MJ: RANK, RANKL and osteoprotegerin in bone biology and disease. Curr Rev Musculoskelet Med 2: 56-64, 2009.

14. Pérez-Sayáns M, Somoza-Martín JM, Barros-Angueira F, Rey JM and García-García A: RANK/RANKL/OPG role in distraction osteogenesis. Oral Surg Oral Med Oral Pathol Oral Radiol Endod 109: 679-686, 2010.

15. Fu YX, Gu JH, Zhang YR, Tong XS, Zhao HY, Yuan Y, Liu XZ, Bian JC and Liu ZP: Osteoprotegerin influences the bone resorption activity of osteoclasts. Int J Mol Med 31: 1411-1417, 2013.
16. Jimi E, Akiyama S, Tsurukai T, Okahashi N, Kobayashi K, Udagawa N, Nishihara T, Takahashi N and Suda T: Osteoclast differentiation factor acts as a multifunctional regulator in murine osteoclast differentiation and function. J Immunol 163: 434-442, 1999.

17. Lee SE, Woo KM, Kim SY, Kim HM, Kwack K, Lee ZH and Kim HH: The phosphatidylinositol 3-kinase, p38, and extracellular signal-regulated kinase pathways are involved in osteoclast differentiation. Bone 30: 71-77, 2002.

18. Li X, Udagawa N, Itoh K, Suda K, Murase Y, Nishihara T, Suda T and Takahashi N: p38 MAPK-mediated signals are required for inducing osteoclast differentiation but not for osteoclast function. Endocrinology 143: 3105-3113, 2002.

19. Junttila MR, Li SP and Westermarck J: Phosphatase-mediated crosstalk between MAPK signaling pathways in the regulation of cell survival. FASEB J 22: 954-965, 2008.

20. Theoleyre S, Wittrant Y, Couillaud S, Vusio P, Berreur M, Dunstan C, Blanchard F, Rédini F and Heymann D: Cellular activity and signaling induced by osteoprotegerin in osteoclasts: Involvement of receptor activator of nuclear factor kappaB ligand and MAPK. Biochim Biophys Acta 1644: 1-7, 2004.

21. Mladenović Ž, Johansson A, Willman B, Shahabi K, Björn E and Ransjö M: Soluble silica inhibits osteoclast formation and bone resorption in vitro. Acta Biomater 10: 406-418, 2014.

22. Chen X, Zhu G, Jin T, Gu S, Xiao H and Qiu J: Cadmium induces differentiation of RAW264.7 cells into osteoclasts in the presence of RANKL. Food Chem Toxicol 49: 2392-2397, 2011.

23. Fu YX, Gu JH, Zhang YR, Tong XS, Zhao HY, Yuan Y, Liu XZ, Bian JC and Liu ZP: Inhibitory effects of osteoprotegerin on osteoclast formation and function under serum-free conditions. J Vet Sci 14: 405-412, 2013.

24. Simonet WS, Lacey DL, Dunstan CR, Kelley M, Chang MS, Lüthy R, Nguyen HQ, Wooden S, Bennett L, Boone T, et al: Osteoprotegerin: A novel secreted protein involved in the regulation of bone density. Cell 89: 309-319, 1997.

25. Boyle WJ, Simonet WS and Lacey DL: Osteoclast differentiation and activation. Nature 423: 337-342, 2003.

26. Hofbauer LC: Osteoprotegerin ligand and osteoprotegerin: Novel implications for osteoclast biology and bone metabolism. Eur J Endocrinol 141: 195-210, 1999.

27. Wong BR, Besser D, Kim N, Arron JR, Vologodskaia M, Hanafusa $\mathrm{H}$ and Choi Y: TRANCE, a TNF family member, activates Akt/PKB through a signaling complex involving TRAF6 and c-Src. Mol Cell 4: 1041-1049, 1999.

28. Shih J, Bauer D, Orloff J, Capizzi T, Thompson D, Oppenheimer L and Ross PD: Proportion of fracture risk reduction explained by BMD changes using Freedman analysis depends on choice of predictors. Osteoporos Int 13: S38-S39, 2002.

29. Miyazaki T, Katagiri H, Kanegae Y, Takayanagi H, Sawada Y, Yamamoto A, Pando MP, Asano T, Verma IM, Oda H, et al: Reciprocal role of ERK and NF-kappaB pathways in survival and activation of osteoclasts. J Cell Biol 148: 333-342, 2000.

30. David JP, Rincon M, Neff L, Horne WC and Baron R: Carbonic anhydrase II is an AP-1 target gene in osteoclasts. J Cell Physiol 188: 89-97, 2001.

31. Ye H, Arron JR, Lamothe B, Cirilli M, Kobayashi T, Shevde NK, Segal D, Dzivenu OK, Vologodskaia M, Yim M, et al: Distinct molecular mechanism for initiating TRAF6 signalling. Nature 418: 443-447, 2002.

32. Blair HC, Robinson LJ and Zaidi M: Osteoclast signalling pathways. Biochem Biophys Res Commun 328: 728-738, 2005.

33. Mizukami J, Takaesu G, Akatsuka H,Sakurai H,Ninomiya-Tsuji J, Matsumoto K and Sakurai N: Receptor activator of NF-kappaB ligand (RANKL) activates TAK1 mitogen-activated protein kinase kinase kinase through a signaling complex containing RANK, TAB2, and TRAF6. Mol Cell Biol 22: 992-1000, 2002.

34. Choi HJ, Park YR, Nepal M, Choi BY, Cho NP, Choi SH, Heo SR, Kim HS, Yang MS and Soh Y: Inhibition of osteoclastogenic differentiation by Ikarisoside A in RAW 264.7 cells via JNK and NF-kappaB signaling pathways. Eur J Pharmacol 636: 28-35, 2010.

35. Cano E and Mahadevan LC: Parallel signal processing among mammalian MAPKs. Trends Biochem Sci 20: 117-122, 1995.

36. Grigoriadis AE, Wang ZQ, Cecchini MG, Hofstetter W, Felix R, Fleisch HA and Wagner EF: c-Fos: A key regulator of osteoclast-macrophage lineage determination and bone remodeling. Science 266: 443-448, 1994.

37. Chapurlat RD, Palermo L, Ramsay P and Cummings SR: Risk of fracture among women who lose bone density during treatment with alendronate. The Fracture Intervention Trial. Osteoporos Int 16: 842-848, 2005. 
38. Hong SY, Jeon YM, Lee HJ, Kim JG, Baek JA and Lee JC: Activation of RhoA and FAK induces ERK-mediated osteopontin expression in mechanical force-subjected periodontal ligament fibroblasts. Mol Cell Biochem 335: 263-272, 2010.

39. Stanley ER, Berg KL, Einstein DB, Lee PS, Pixley FJ, Wang Y and Yeung YG: Biology and action of colony--stimulating factor-1. Mol Reprod Dev 46: 4-10, 1997.

40. Tsurukai T, Udagawa N, Matsuzaki K, Takahashi N and Suda T: Roles of macrophage-colony stimulating factor and osteoclast differentiation factor in osteoclastogenesis. J Bone Miner Metab 18: 177-184, 2000.

41. Fuller K, Owens JM, Jagger CJ, Wilson A, Moss R and Chambers TJ: Macrophage colony-stimulating factor stimulates survival and chemotactic behavior in isolated osteoclasts. J Exp Med 178: 1733-1744, 1993.
42. Weilbaecher KN, Motyckova G, Huber WE, Takemoto CM, Hemesath TJ, Xu Y, Hershey CL, Dowland NR, Wells AG and Fisher DE: Linkage of M-CSF signaling to Mitf, TFE3, and the osteoclast defect in Mitf(mi/mi) mice. Mol Cell 8: 749-758, 2001.

43. Shiotani A, Takami M, Itoh K, Shibasaki Y and Sasaki T: Regulation of osteoclast differentiation and function by receptor activator of NFkB ligand and osteoprotegerin. Anat Rec 268: 137-146, 2002.

44. Hakeda Y, Kobayashi Y, Yamaguchi K, Yasuda H, Tsuda E, Higashio K, Miyata T and Kumegawa M: Osteoclastogenesis inhibitory factor (OCIF) directly inhibits bone-resorbing activity of isolated mature osteoclasts. Biochem Biophys Res Commun 251: 796-801, 1998. 